Research Article

\title{
Electrochemical Behavior of CsI in LiCl Molten Salt
}

\author{
Sung-Wook Kim $\mathbb{D}^{D}$, Sang-Kwon Lee $\mathbb{D}^{D}$, Min Ku Jeon $\left(\mathbb{D}\right.$, and Eun-Young Choi $\mathbb{I D}^{-}$
}

Korea Atomic Energy Research Institute, Daejeon 34057, Republic of Korea

Correspondence should be addressed to Sung-Wook Kim; swkim818@kaeri.re.kr

Received 15 July 2020; Revised 16 September 2020; Accepted 4 October 2020; Published 15 October 2020

Academic Editor: Peter Ivanov

Copyright (C) 2020 Sung-Wook Kim et al. This is an open access article distributed under the Creative Commons Attribution License, which permits unrestricted use, distribution, and reproduction in any medium, provided the original work is properly cited.

\begin{abstract}
The electrochemical behavior of CsI in $\mathrm{LiCl}$ molten salt was investigated to identify its impact on the electrolytic oxide reduction of oxide-phase spent nuclear fuels by combined electrolysis and cyclic voltammetry experiments of LiCl-CsI in comparison with $\mathrm{LiCl}, \mathrm{LiCl}-\mathrm{CsCl}$, and $\mathrm{LiCl}-\mathrm{LiI}$. It was found that $\mathrm{Cs}^{+}$ions were hardly involved in the cathode reaction, and reduction of $\mathrm{Li}^{+}$ions occurred dominantly in the cathode. In contrast, incorporation of $\mathrm{I}^{-}$ions induced low-potential anode reaction compared with the $\mathrm{I}^{-}$ion-free cases. Such additional electrochemical reaction resulted in the generation of $\mathrm{I}_{2}$ and/or ICl gases, which would increase a process burden for treating ${ }^{129}$ I with exceptionally long lifetime. In this respect, separating CsI from spent nuclear fuel before the electrolytic oxide reduction is recommended for the purpose of efficient waste management.
\end{abstract}

\section{Introduction}

Electrolytic oxide reduction (EOR) has been developed as a technical option of oxide reduction in pyroprocessing [1-3]. Spent nuclear fuels (SNFs) in oxide forms (mainly, $\mathrm{UO}_{2}$ ) are electrochemically reduced to metallic forms during the EOR process [1-3]. Then, the metal products are electrochemically treated for the recovery of uranium and transuranic elements [1-3]. The EOR process generally utilizes $\mathrm{LiCl}$ molten salt (at $650^{\circ} \mathrm{C}$ ) as an electrolyte [4-6]. Due to the nature of electrochemical reactions, the EOR process can be divided into two parts: the reduction of SNFs at the cathode and the gas evolution at the anode. The cathode reaction can be simply expressed as

$$
\mathrm{UO}_{2}+4 \mathrm{Li}^{+}+4 \mathrm{e}^{-} \longrightarrow \mathrm{UO}_{2}+4 \mathrm{Li}(\mathrm{l}) \longrightarrow \mathrm{U}+4 \mathrm{Li}^{+}+2 \mathrm{O}^{2-}
$$

The anode reaction aims to remove $\mathrm{O}^{2-}$ ions released from the SNFs as a result of the cathode reaction. In a conventional $\mathrm{Pt}$ anode system, $\mathrm{O}^{2-}$ ions are oxidized at the anode to evolve $\mathrm{O}_{2}$ gas to maintain the reaction homeostasis [6].

$$
2 \mathrm{O}^{2-} \longrightarrow \mathrm{O}_{2}(\mathrm{~g})+4 \mathrm{e}^{-}
$$

A C anode system has been developed to replace the costly $\mathrm{Pt}$ anode [7-9]. The anode reaction becomes complicated in the $\mathrm{C}$ anode system, in which $\mathrm{O}^{2-}$ ions can be eliminated by various (electro)chemical pathways related to $\mathrm{O}_{2}, \mathrm{Cl}_{2}$, and $\mathrm{CO} / \mathrm{CO}_{2}$ evolution [7].

Several fission products (e.g., $\mathrm{Cs}, \mathrm{Ba}$, and $\mathrm{Sr}$ ) in SNFs are highly soluble in $\mathrm{LiCl}$ molten salt, and hence, they are thought to accumulate in the electrolyte during the EOR process $[4,5]$. They may play a role in the electrochemistry of the EOR process, which may affect charge efficiency and, subsequently, quality of the metal products. It was reported that that the dissolution of $\mathrm{Ba}$ and $\mathrm{Sr}$ in the $\mathrm{LiCl}$ electrolyte has little effect on the EOR process $[5,10]$. In contrast, incorporation of $\mathrm{Cs}$ in the electrolyte (at more than $10 \mathrm{wt} . \%$ of $\mathrm{CsCl}$ in $\mathrm{LiCl}$ ) was revealed to hinder the proper reduction of $\mathrm{UO}_{2}$ [5]. The literature utilized $\mathrm{CsCl}$ as the Cs source, and the effect of $\mathrm{Cs}^{+}$ions to the EOR reaction was investigated [5]. CsI is one of the possible chemical forms of Cs in SNFs [11]. Because the dissolution of CsI to the $\mathrm{LiCl}$ electrolyte provides $\mathrm{I}^{-}$ions, the impact of $\mathrm{I}^{-}$ions on the EOR reaction needs to be identified.

Compounds of Cs, including CsI, in SNFs are expected to be removed by high-temperature heat treatment to form volatile phases $[12,13]$. Thus, performing heat treatment is 
considered to be beneficial for the EOR process $[1,5]$. On the other hand, direct transportation of SNFs, without the heat treatment, to the EOR reactor after physical decladding remains a viable approach in terms of process simplicity, and such an approach was used in research involving EOR experiments conducted in the United States and in Japan $[4,5]$.

In this respect, it is meaningful to identify how the dissolved CsI behaves during the EOR process, and in this present study, the electrochemical behavior of an LiCl-CsI system was investigated to determine the impact of CsI accumulation in the $\mathrm{LiCl}$ electrolyte on the EOR process. Graphite was employed as the $\mathrm{C}$ anode material because of its wide process window to the Pt anode.

\section{Materials and Methods}

Electrochemical investigation was undertaken inside an Arfilled glove box. Several combinations of $\mathrm{LiCl}$ (99\%, Alfa Aesar), CsCl (99.9\%, Alfa Aesar), LiI (99.95\%, Alfa Aesar), and CsI (99.9\%, Alfa Aesar) were separately prepared for the electrochemical investigation. Figure 1 shows the electrochemical cell used in this study. The electrochemical cell had three electrode slots in triangular arrangement (interelectrode distance $=32 \mathrm{~mm}$ ). The electrodes were covered with $\mathrm{Al}_{2} \mathrm{O}_{3}$ tubes for insulation when they were introduced into the electrochemical cell. An $\mathrm{MgO}$ crucible (inner diameter $=52 \mathrm{~mm}$ ) containing the molten salt components was placed at the bottom of the electrochemical cell. An Ar purge gas $\left(100 \mathrm{~mL} \mathrm{~min}^{-1}\right)$ was introduced continuously to the electrochemical cell to get rid of corrosive gas-phase reaction products (e.g., $\mathrm{Cl}_{2}$ and $\mathrm{I}_{2}$ ). The electrochemical experiments were carried out at $650^{\circ} \mathrm{C}$. The electrolysis experiment was done using a $\mathrm{Ni}$ wire (diameter $=2 \mathrm{~mm}$, Nilaco) as cathode and a graphite rod (diameter $=3 \mathrm{~mm}$, Alfa Aesar) as anode. For the cyclic voltammetry (CV) investigation, the Ni wire (or, the graphite rod) working electrode and the graphite rod (or, the Ni wire) counterelectrode were used, and an additional $\mathrm{Ni}$ wire was employed as a quasi-reference electrode (QRE). The electrolysis experiment was controlled by a power supply (E3633A, Keysight), and the CV experiment was conducted using a potentiostat (PGSTAT362N, Autolab). The electrolysis product recovered from the cathode was dissolved into deionized water for chemical analysis. Concentrations of $\mathrm{Li}$, Cs, and I in the dissolved solution were analyzed by inductively coupled plasma-mass spectroscopy (iCAP Qc, Thermo Scientific), and ion chromatography (ICFLEX 930, Metrohm) was used to identify the $\mathrm{Cl}^{-}$ion concentration in the solution. Thermodynamic calculation was done using HSC Chemistry 9.0 software (Outotec) for calculation of the electrolysis voltage of each species.

\section{Results and Discussion}

To track the electrochemical behavior of CsI in the $\mathrm{LiCl}$ electrolyte briefly, the current-voltage relationship of the LiCl-CsI molten salt $(\mathrm{Li} / \mathrm{Cs}=\mathrm{Cl} / \mathrm{I}=3 / 1)$ was characterized, as shown in Figure 2. Identical experiments were also carried out with pure $\mathrm{LiCl}, \mathrm{LiCl}-\mathrm{CsCl}(\mathrm{Li} / \mathrm{Cs}=3 / 1)$, and $\mathrm{LiCl}-\mathrm{LiI}(\mathrm{Cl} /$ $\mathrm{I}=3 / 1$ ) systems to clearly identify the effect of the

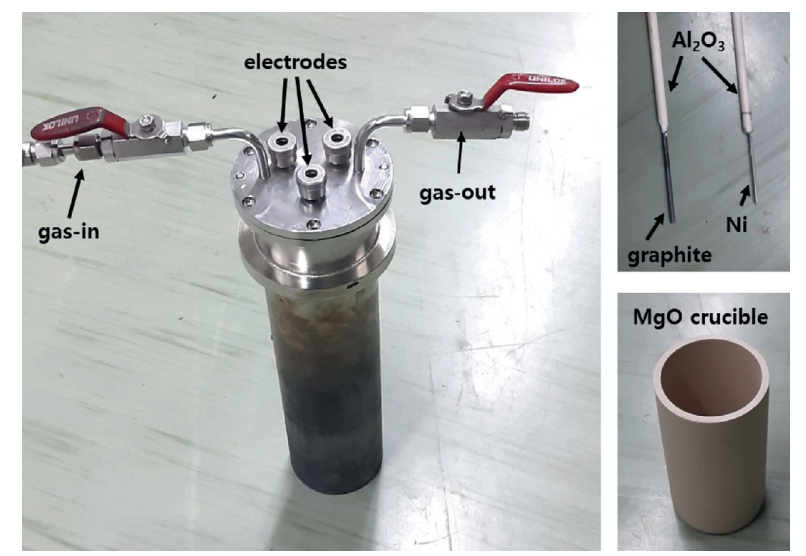

FIgure 1: Configuration of electrochemical cell used for the electrochemical investigation.

introduction of $\mathrm{Cs}^{+}$and $\mathrm{I}^{-}$ions (Figure 2). Because the electrode immersion depth (due to difficulty in precise control) and the ionic transports (due to different composition) are not identical for each system, which directly influence the electrochemical properties, the original current data in Figure 2(a) were normalized, as shown in Figure 2(b), for comparison. From this, the electrolysis behavior can be categorized into two groups: the I-containing molten salts (LiCl-CsI and LiCl-LiI) were activated at a low-voltage range $(>2.5 \mathrm{~V})$, while the others $(\mathrm{LiCl}$ and $\mathrm{LiCl}-\mathrm{CsCl})$ required a high voltage $(>3.5 \mathrm{~V})$ for initiating the electrochemical reaction. It means that the existence of $\mathrm{I}^{-}$ions in the $\mathrm{LiCl}$ electrolyte induces the additional electrochemical reaction during the EOR process.

Table 1 describes the Gibbs free energy change $(\Delta G)$ of the decomposition reactions of $\mathrm{LiCl}, \mathrm{CsI}, \mathrm{CsCl}$, and $\mathrm{LiI}$ and their corresponding electrolysis voltage at the reaction temperature $\left(650^{\circ} \mathrm{C}\right)$. The activation voltage of the I-containing systems was less than that of the I-free systems, demonstrating that the low-voltage reaction resulted from the existence of $\mathrm{I}^{-}$ions. The onset voltage of the I-containing molten salt (Figure 2) is well matched to the electrolysis voltage of LiI, suggesting that $\mathrm{Li}^{+}$and $\mathrm{I}^{-}$ions dominantly participated in the electrochemical reaction at the cathode and the anode at this condition, respectively.

Identification of the cathode reaction is a key in designing the EOR process because the main reaction products, the reduced SNFs, are fabricated at the cathode. It is believed that the electrochemically deposited Li metal works as a reducing agent of the oxide SNFs. Side reactions occurring at the cathode may result in decreased metal conversion efficiency because they consume electrons. However, it is difficult to determine whether $\mathrm{Cs}^{+}$ions contribute to the cathode reactions from the experimental results given in Figure 2. In this respect, constant-voltage electrolysis operations were conducted at $5 \mathrm{~V}$ using the LiCl-CsI molten salt $(\mathrm{LiCl} / \mathrm{CsI}=3 / 1)$ to collect the deposition product formed on the Ni electrode (i.e., cathode), as shown in Figure 3. The induced current during the constant-voltage operation was comparable with the current-voltage data in Figure 2(a). Figure 3 shows the deposition product, a shiny silver-colored 


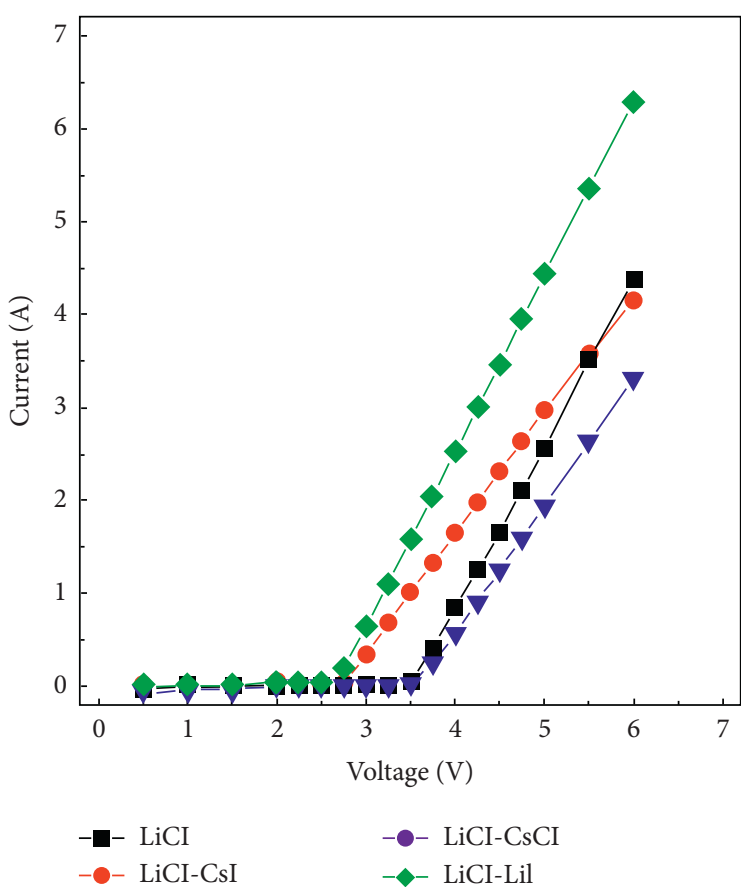

(a)

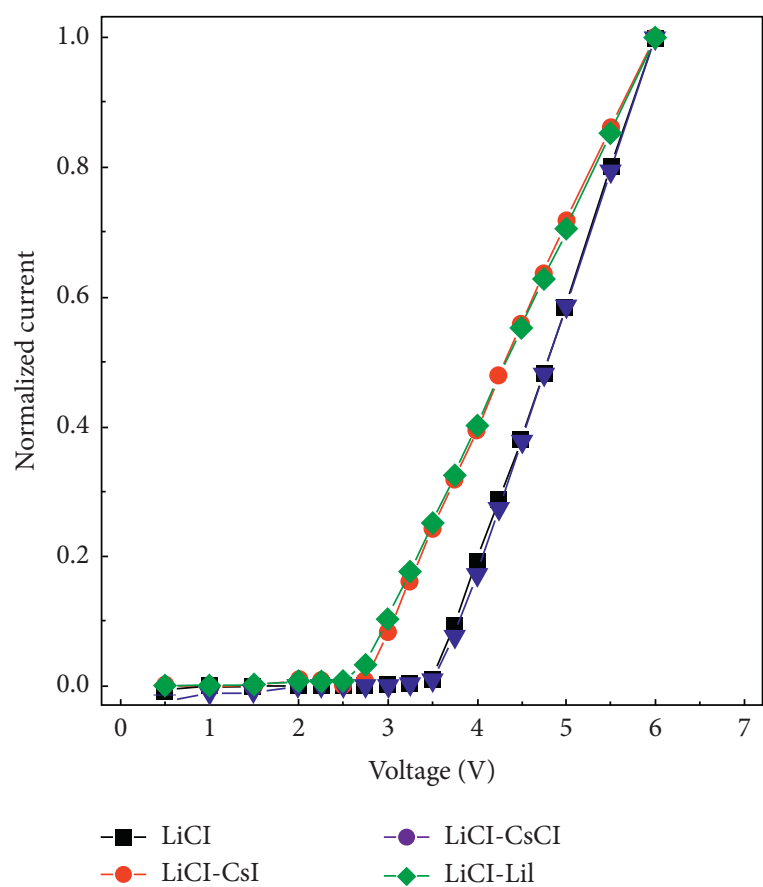

(b)

Figure 2: Current-voltage characteristics of the LiCl, LiCl-CsI, LiCl-LiI, and LiCl-CsCl molten salts: (a) original data and (b) normalized data.

TABLE 1: $\Delta \mathrm{G}$ values and corresponding electrolysis voltage of decomposition reactions of $\mathrm{LiCl}, \mathrm{CsI}, \mathrm{CsCl}$, and $\mathrm{LiCl}$ at $650^{\circ} \mathrm{C}$.

\begin{tabular}{lcc}
\hline Reaction & $\Delta \mathrm{G}(\mathrm{kJ})$ & Electrolysis voltage $(\mathrm{V})$ \\
\hline $2 \mathrm{LiCl}(\mathrm{l})=2 \mathrm{Li}(\mathrm{l})+\mathrm{Cl}_{2}(\mathrm{~g})$ & +667.411 & 3.46 \\
$2 \mathrm{CsCl}(\mathrm{l})=2 \mathrm{Cs}(\mathrm{l})+\mathrm{Cl}_{2}(\mathrm{~g})$ & +706.190 & 3.66 \\
$2 \mathrm{LiI}(\mathrm{l})=2 \mathrm{Li}(\mathrm{l})+\mathrm{I}_{2}(\mathrm{~g})$ & +476.966 & 2.47 \\
$2 \mathrm{CsI}(\mathrm{l})=2 \mathrm{Cs}(\mathrm{l})+\mathrm{I}_{2}(\mathrm{~g})$ & +584.456 & 3.02 \\
\hline
\end{tabular}

metal deposit. The atomic ratio of the deposit was identified to reveal what the cathode reaction is (Table 2). It should be noted that the atomic ratio is not highly reliable for several reasons, including residual molten salt species on the surface of the metal deposit, floating behavior of metal droplets of $\mathrm{Li}$ (melting point $=180.5^{\circ} \mathrm{C}$ ) and $\mathrm{Cs}\left(\right.$ melting point $\left.=28.44^{\circ} \mathrm{C}\right)$, and evaporation of $\mathrm{Cs}$ metal (boiling point $=670.8^{\circ} \mathrm{C}$ ), which are not controllable. Nevertheless, it is remarkable that the $\mathrm{Li}$ content was much higher than that of the other elements. This suggests that $\mathrm{Li}^{+}$ions are the major cation species participating in the cathode reaction in this system. The detected anion species (e.g., $\mathrm{Cl}$ and I) from the deposit seemed to have originated from the residual electrolyte, and the comparison of $\mathrm{Cl} / \mathrm{I}$ ratio of the deposit with that of the electrolyte well supported this. The I/Cs ratio was greater than in the original molten salt, claiming the loss of Cs during the reaction. The electrochemically deposited Cs metal might escape from the surface of the cathode electrode (i.e., Ni wire in this case) by forming floating metal droplets and/or the vapor phase. Consequently, the small amount of $\mathrm{Cs}^{+}$ions in the molten salt could be involved in the electrochemical reaction at the cathode.
The actual Cs content in the EOR electrolyte that treated the SNFs was only hundreds of ppm [4], but the electrolysis study described above was conducted at a highly concentrated condition to clearly distinguish the impact of CsI. In this respect, an additional electrochemical investigation was made with low-concentration LiCl-CsI (0.5 wt.\% CsI) molten salt. Compared with the high-concentration experiment, the low-voltage electrolysis was not that distinctive in this case because of the low $\mathrm{I}^{-}$content (Figure 4). The onset voltage of the electrochemical reaction increased $(>3.0 \mathrm{~V})$ with reducing CsI concentration. Figure 5 shows the CV curves of the low-concentration LiCl-CsI molten salt in comparison with pure LiCl. Typical Li metal deposition characteristics were identified at the cathode below $-2.1 \mathrm{~V}$ vs. Ni QRE (Figures 5(a) and 5(c)) [10], as expected, showing the negligible effect of the $\mathrm{Cs}^{+}$ion. The CV curves obtained from the anode side, however, showed completely different behaviors (Figures 5(b) and 5(d)), demonstrating that the additional electrochemical reaction related to $\mathrm{I}^{-}$ ions took place. The anodic peak appeared at around $+0.9 \mathrm{~V}$ vs. Ni QRE (+1.3 V vs. Ni QRE for pure $\mathrm{LiCl}$ case), which is $+3.0 \mathrm{~V}$ from the $\mathrm{Li}$ deposition potential. The potential difference is comparable with the onset voltage in Figure 4. The increased potential difference in this case to the highconcentration experiment seems to be due to concentration polarization of the $\mathrm{I}_{2}$ evolution at the low $\mathrm{I}^{-}$concentration and/or evolution of $\mathrm{ICl}$ gases (e.g., $\mathrm{LiCl}(\mathrm{l})+\mathrm{LiI}(\mathrm{l})$ $=2 \mathrm{Li}(\mathrm{l})+\mathrm{ICl}(\mathrm{g})$; electrolysis voltage $=2.87 \mathrm{~V})$. The $\mathrm{ICl}$ gases also can be formed by chemical reaction of $\mathrm{I}_{2}$ and $\mathrm{Cl}_{2}$ gases (potential anode products) $\left(\mathrm{I}_{2}(\mathrm{~g})+\mathrm{Cl}_{2}(\mathrm{~g})=\mathrm{ICl}(\mathrm{g}) ; \Delta \mathrm{G}=\right.$ $38.231 \mathrm{~kJ}$ at $\left.650^{\circ} \mathrm{C}\right)$. 


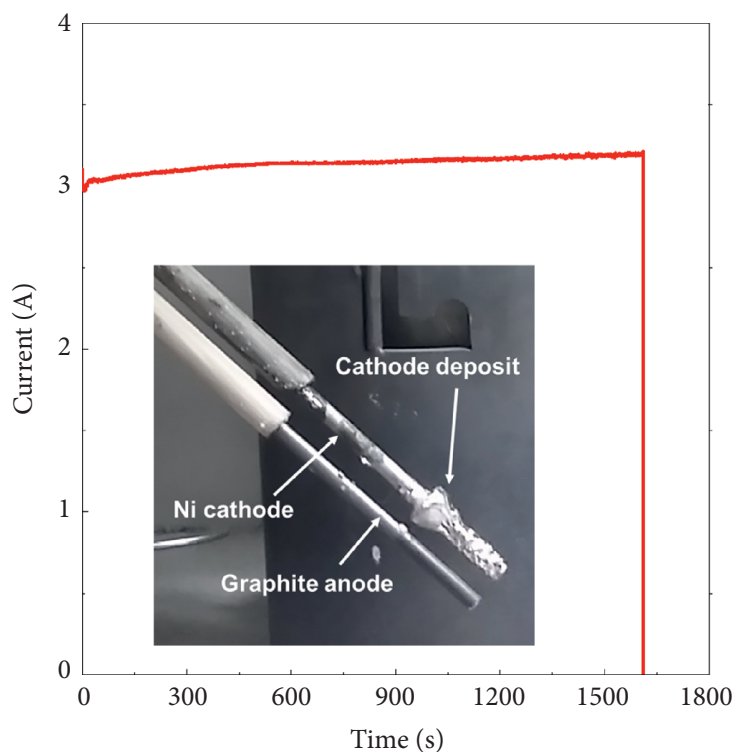

FIGURE 3: Current response versus time during the constant-voltage electrolysis of the LiCl-CsI molten salt (inset: electrodes recovered after the electrolysis).

TABle 2: Atomic ratio of the cathode deposit obtained by the constant-voltage electrolysis of the LiCl-CsI molten salt.

\begin{tabular}{lcccc}
\hline & $\mathrm{Li} / \mathrm{Cs}$ & $\mathrm{Cl} / \mathrm{I}$ & $\mathrm{I} / \mathrm{Cs}$ & $\mathrm{Cl} / \mathrm{Li}$ \\
\hline Atomic ratio & 244.50 & 3.05 & 1.51 & 0.02 \\
\hline
\end{tabular}

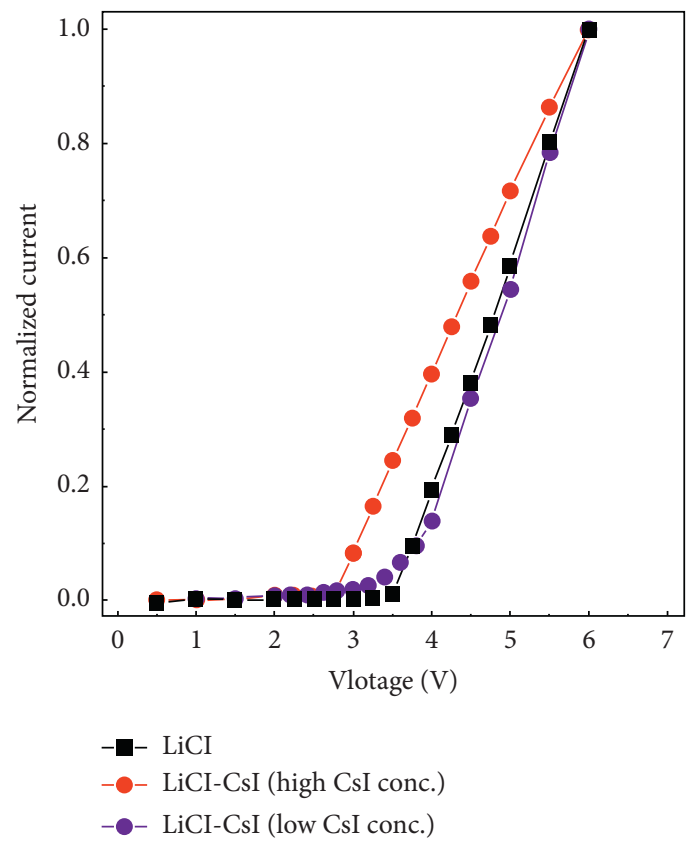

FIgURE 4: Normalized current-voltage characteristics of the $\mathrm{LiCl}$ and LiCl-CsI molten salts with the different CsI concentrations.

Consequently, it is concluded that the CsI accumulation in the LiCl electrolyte greatly affects the anode reaction of the EOR process. $\mathrm{I}^{-}$ions are easily oxidized to form gas phases $\left(\mathrm{I}_{2}\right.$ and/or $\mathrm{ICl}$ ) as described above. Generating the I-containing gas phases becomes a critical issue in the design of the whole EOR process, from the electrochemical reaction to the post-EOR treatments. With respect to final disposal,
${ }^{129} \mathrm{I}$ is a challenging fission product because of its extremely long half-life $\left(1.57 \times 10^{7} \mathrm{y}\right)$ and high mobility in the environment $[14,15]$. The exhaust gas of the $\mathrm{C}$ anode-based EOR process is a complex of $\mathrm{Cl}_{2}, \mathrm{O}_{2}, \mathrm{CO}, \mathrm{CO}_{2}$, and $\mathrm{Ar}$ [7], and it may also contain the vapor phases of $\mathrm{LiCl}(-\mathrm{CsI})$ molten salt, $\mathrm{Li}$ metal, and Cs metal. Introduction of the $\mathrm{I}_{2}$ and $\mathrm{ICl}$ gases should accompany complicated gas treatment systems 


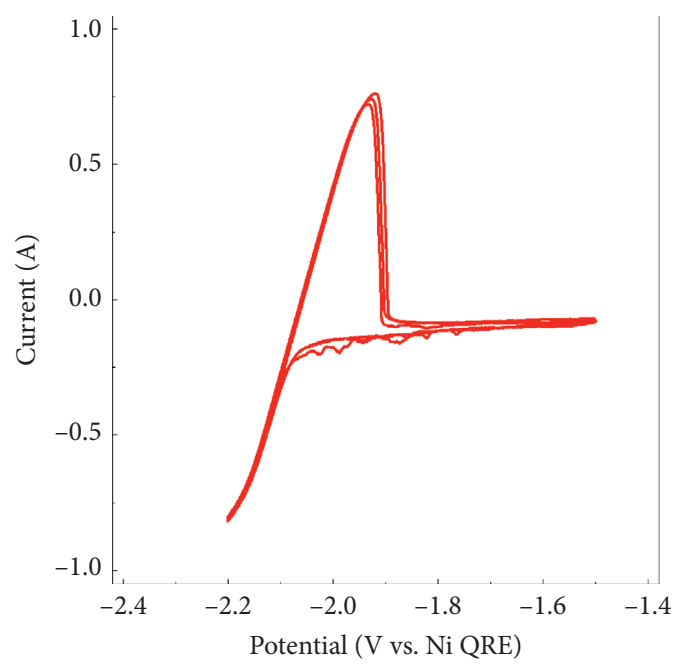

(a)

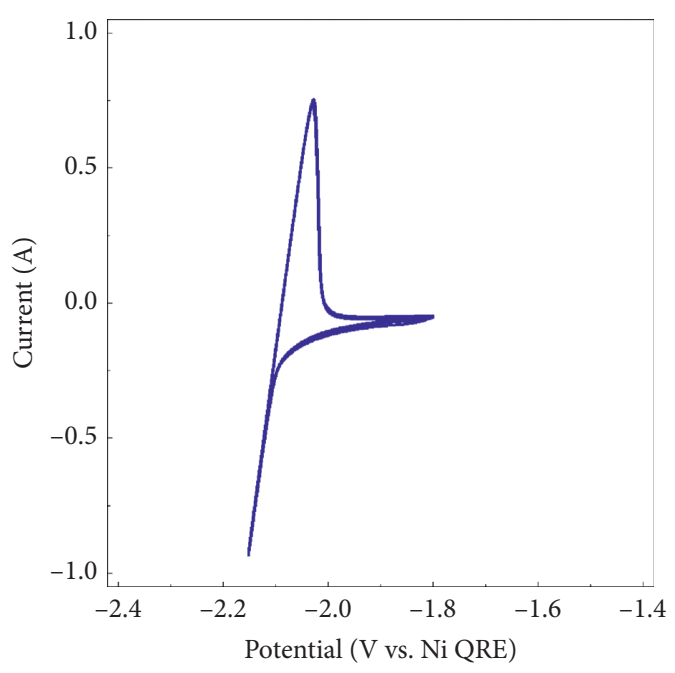

(c)

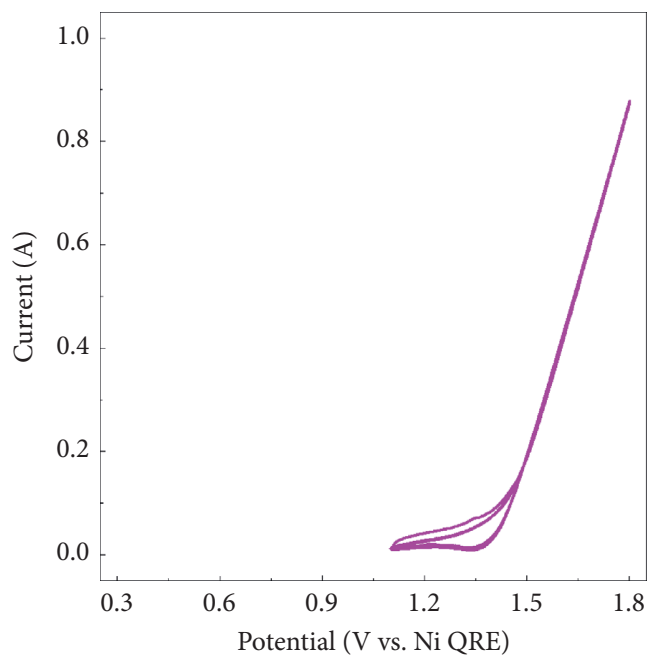

(b)

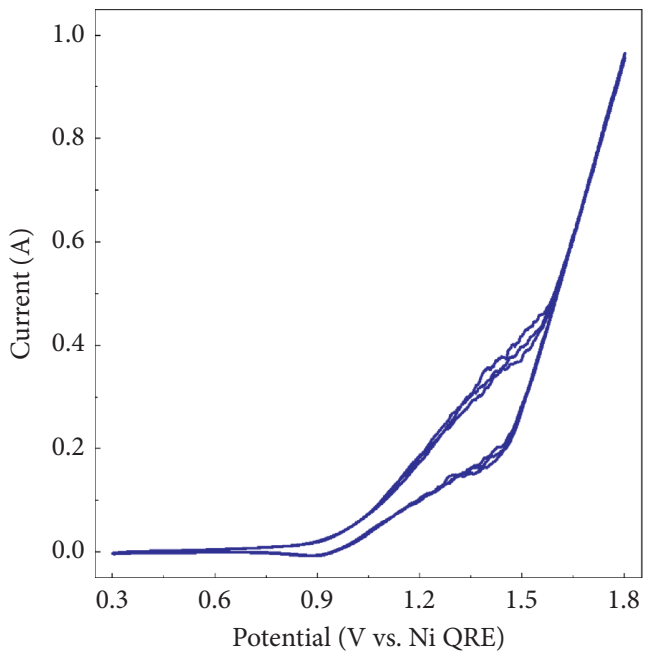

(d)

Figure 5: CV investigation of the (a, b) LiCl and (c, d) LiCl-CsI molten salts for the (a, c) cathode and the (b, d) anode.

because ${ }^{129} \mathrm{I}$, even in a very small amount, should be effectively separated from a profound amount of the complicated EOR exhaust gas stream for disposal. Thus, the transportation of CsI to the $\mathrm{LiCl}$ molten salt electrolyte will require a large gas treatment system, which becomes an additional process burden on the whole EOR process. Meanwhile, the CsI treatment technique has been well established as a head-end process, from volatilization to the immobilization, as the pre-EOR process of pyroprocessing $[1,12,13]$. Subsequently, it is considered that the removal of CsI from SNFs before EOR processing is a better strategy in terms of the integrated process efficiency of the EOR process and also the whole pyroprocessing.

\section{Conclusions}

Comparative electrolysis experiments of $\mathrm{LiCl}$, LiCl-CsI ( $\mathrm{Li} /$ $\mathrm{Cs}=\mathrm{Cl} / \mathrm{I}=3 / 1), \mathrm{LiCl}-\mathrm{CsCl}(\mathrm{Li} / \mathrm{Cs}=3 / 1)$, and LiCl-LiI $(\mathrm{Cl} /$ $\mathrm{I}=3 / 1)$ molten salts were carried out to reveal the impact of CsI, a component of SNFs, in the EOR electrolyte system. The onset voltage of the electrolysis of the I-containing group (LiCl-CsI and LiCl-LiI) $(\sim 2.5 \mathrm{~V})$ was lower than that of the I-free group ( $\mathrm{LiCl}$ and $\mathrm{LiCl}-\mathrm{CsCl})(\sim 3.5 \mathrm{~V})$, showing that the incorporation of $\mathrm{I}^{-}$ions induced a low-voltage reaction. On the contrary, the electrolysis behaviors of $\mathrm{LiCl}$ and $\mathrm{LiCl}-\mathrm{CsCl}$ (or, LiCl-CsI and LiCl-LiI) were comparable, and it was considered that the $\mathrm{Cs}^{+}$ion incorporation did not have a significant effect in the electrochemical reaction. Chemical analysis on the cathode product of the LiCl-CsI electrolysis revealed the preferential deposition of the Li metal. These results agreed with the CV investigation performed with the lower CsI concentration (CsI $=0.5$ wt.\%). In this concentration, the oxidation potential of $\mathrm{I}^{-}$ions $(+0.9 \mathrm{~V}$ vs. Ni QRE) was lower than that of $\mathrm{Cl}^{-}$ions $(+1.3 \mathrm{~V}$ vs. QRE) at the anode side, while no signal of additional reactions was found at the cathode side. Thus, the I-containing gases (such as $\mathrm{I}_{2}$ or ICl) are expected to be generated during the EOR process when CsI is incorporated to the $\mathrm{LiCl}$ electrolyte. Considering the complexity of the exhaust gas treatment system for handling the I-containing gases (due to long lifetime of ${ }^{129} \mathrm{I}$ ), separating 
CsI from SNFs before the EOR process is regarded as a reasonable option compared to the direct transport of SNFs to the EOR system.

\section{Data Availability}

The data used to support the findings of the study are available from the corresponding author upon request.

\section{Conflicts of Interest}

The authors declare that there are no conflicts of interest regarding the publication of this paper.

\section{Acknowledgments}

This work was supported by the National Research Foundation of Korea (NRF) grant funded by the Korea Government (MISP) (2017M2A8A5015077).

\section{References}

[1] H. Lee, G.-I. Park, J.-W. Lee et al., "Current status of pyroprocessing development at KAERI," Science and Technology of Nuclear Installations, vol. 2013, Article ID 343492, 2013.

[2] T. Inoue and L. Koch, "Development of pyroprocessing and its future direction," Nuclear Engineering and Technology, vol. 40, no. 3, pp. 183-190, 2008.

[3] E. J. Karell, K. V. Gourishankar, J. L. Smith, L. S. Chow, and L. Redey, "Separation of actinides from LWR spent fuel using molten-salt-based electrochemical processes," Nuclear Technology, vol. 136, no. 3, pp. 342-353, 2001.

[4] S. Herrmann, S. Li, and M. Simpson, "Electrolytic reduction of spent light water reactor fuel bench-scale experiment results," Journal of Nuclear Science and Technology, vol. 44, no. 3, pp. 361-367, 2007.

[5] Y. Sakamura, "Effect of alkali and alkaline-earth chloride addition on electrolytic reduction of $\mathrm{UO}_{2}$ in $\mathrm{LiCl}$ salt bath," Journal of Nuclear Materials, vol. 412, no. 1, pp. 177-183, 2011.

[6] E.-Y. Choi, J. Lee, D. H. Heo, and J.-M. Hur, "Quantitative analysis of oxygen gas exhausted from anode through in situ measurement during electrolytic reduction," Science and Technology of Nuclear Installations, vol. 2017, p. 2748302, 2017.

[7] S.-W. Kim, M. K. Jeon, H. W. Kang et al., "Carbon anode with repeatable use of $\mathrm{LiCl}$ molten salt for electrolytic reduction in pyroprocessing," Journal of Radioanalytical and Nuclear Chemistry, vol. 310, no. 1, pp. 463-467, 2016.

[8] A. Merwin, P. Motsegood, J. Willit, and M. A. Williamson, “A parametric study of operating carbon anodes in the oxide reduction process," Journal of Nuclear Materials, vol. 511, pp. 297-303, 2018.

[9] S.-W. Kim, D. H. Heo, S. K. Lee et al., "A preliminary study of pilot-scale electrolytic reduction of $\mathrm{UO}_{2}$ using a graphite anode," Nuclear Engineering and Technology, vol. 49, no. 7, pp. 1451-1456, 2017.

[10] S.-W. Kim, M. K. Jeon, and E.-Y. Choi, "Electrolytic behavior of $\mathrm{SrCl}_{2}$ and $\mathrm{BaCl}_{2}$ in $\mathrm{LiCl}$ molten salt during oxide reduction in pyroprocessing," Journal of Radioanalytical and Nuclear Chemistry, vol. 321, no. 1, pp. 361-365, 2019.

[11] K. Konashi, Y. Siokawa, H. Kayano, and M. Yamawaki, "Radiation effect on the chemical state of fission product iodine," Journal of Nuclear Materials, vol. 248, pp. 220-225, 1997.

[12] J. H. Yang, J. Y. Yoon, S.-M. Hong, J. H. Lee, and Y.-Z. Cho, "An efficient capture of cesium from cesium iodide (CsI) offgas by aluminosilicate sorbents in the presence of oxygen," Journal of Industrial and Engineering Chemistry, vol. 77, pp. 146-153, 2019.

[13] G.-I. Park, M. K. Jeon, J.-H. Choi et al., "Recent progress in waste treatment technology for pyroprocessing at KAERI," Journal of Nuclear Fuel Cycle and Waste Technology (JNFCWT), vol. 17, no. 3, pp. 279-298, 2019.

[14] B. J. Riley, J. D. Vienna, D. M. Strachan, J. S. McCloy, and J. L. Jerden Jr., "Materials and processes for the effective capture and immobilization of radioiodine: a review," Journal of Nuclear Materials, vol. 470, pp. 307-326, 2016.

[15] H. Tanabe, T. Sakuragi, K. Yamaguchi, T. Sato, and H. Owada, "Development of new waste forms to immobilize iodine-129 released from a spent fuel reprocessing plant," Advances in Science and Technology, vol. 73, pp. 158-170, 2010. 